Review

\title{
Near Field Communication: Technology and Market Trends
}

\author{
Gabriella Arcese $^{\dagger, *}$, Giuseppe Campagna ${ }^{\dagger}$, Serena Flammini ${ }^{\dagger}$ and Olimpia Martucci $^{\dagger}$ \\ Department of Business Studies, Roma Tre University, via Silvio D’Amico 77, 00145 Rome, Italy; \\ E-Mails: giuseppe.campagna@uniroma3.it (G.C.); serena.flammini@uniroma3.it (S.F.); \\ olimpia.martucci@uniroma3.it (O.M.) \\ $\dagger$ These authors contributed equally to this work. \\ * Author to whom correspondence should be addressed; E-Mail: gabriella.arcese@uniroma3.it; \\ Tel.: +39-06-5733-5713; Fax: +39-06-5733-5797.
}

Received: 30 April 2014; in revised form: 15 July 2014 / Accepted: 27 August 2014 / Published: 5 September 2014

\begin{abstract}
Among the different hi-tech content domains, the telecommunications industry is one of the most relevant, in particular for the Italian economy. Moreover, Near Field Communication (NFC) represents an example of innovative production and a technological introduction in the telecommunications context. It has a threefold function: card emulator, peer-to-peer communication and digital content access, and it could be pervasively integrated in many different domains, especially in the mobile payment one. The increasing attention on NFC technology from the academic community has improved an analysis on the changes and the development perspective about mobile payments. It has considered the work done by the GSMA (Global System for Mobile Communications Association) and the NFC Forum in recent years. This study starts from an analysis of the scientific contributions to Near Field Communication and how the main researches on this topic were conceived. Our focus is on the diffusion rates, the adoption rates and the technology life cycle. After that, we analyze the technical-economical elements of NFC. Finally, this work presents the state of art of the improvements to this technology with a deeper focus on NFC technologies applied to the tourism industry. In this way, we have done a case analysis that shows some of the NFC existent applications linked to each stage of the tourism value chain.
\end{abstract}

Keywords: NFC—Near Field Communication; market trends; mobile payment; tourism applications; technological innovation 


\section{Introduction}

The telecommunication field is one of the most innovative sectors, of which Near Field Communication (NFC) is one of the main examples.

The NFC standard was issued in 2003 [1]. It is a data transmission technology that uses short-range radio waves at the specific frequency of $13.56 \mathrm{MHz}$, by which it is possible to read tags that are a kind of passive circuit [2]. This technology, among the different sectors in which it is applied, is also integrated in smartphones. It originates from the evolution of studies and researches in the RFID field, or Radio Frequency Identification [3]. It ranks among the technologies of automatic identification of people, animals and objects, proving to be very important in areas such as logistics, distribution and services [4].

The two technologies, NFC and RFID, have much in common, but one of the main differences between them is demonstrated by the antenna design [5]. Moreover, that the arrangement for the data exchange is no longer a card reader or a typical RFID but a smartphone, is another outstanding element.

The NFC Forum (a no-profit organization founded in 2004 by Philips, Nokia and Sony) developed a highly stable framework for the development of applications, interoperable seamless solutions and safe transactions. The NFC Forum has also coordinated the work of dozens of organizations through the creation of committees and working groups [6].

Near Field Communication has the core RFID technology, and it is able to leverage the existing ecosystem related to payments and contactless ticketing, which involves millions of users [1].

The aim of this work is to provide a comprehensive review oriented to the analysis of the scientific contributions related to NCFs technology, to deepen them through an analysis of its analyze the technical-economical elements. In addition, we show NFC applications in the tourism industry.

\section{Literature Review: Technology Analysis}

This literature review is the result of research of NFC related articles, reports and studies. It takes place from the research conducted using search engines Scopus, ISI Web Knowledge, Google Scholar and Google Chrome.

According to Haselsteiner and Breitfuß [7], Near Field Communication is an efficient technology for communications within short ranges, which offers an intuitive and simple way to transfer data between electronic devices. NFC is based on existing contactless technologies, it has an ecosystem that involves many stakeholders (Figure 1, [8]) and it is compatible with the RFID infrastructures around the world due to the standards mentioned above.

NFC devices can receive and transmit data at the same time [9]. Those NFC devices have many functions: they can operate, for example, as a smart contactless card, as a passive RFID tag and as a medium to exchange data between various devices. NFC devices can also be used to exchange data as text, images and URLs simply by holding the device near various smart tags. Hence, NFC has a wide applicability across a wide spectrum of enterprises. 
Figure 1. Near Field Communication stakeholder ecosystem (source: authors' elaboration based on [8].

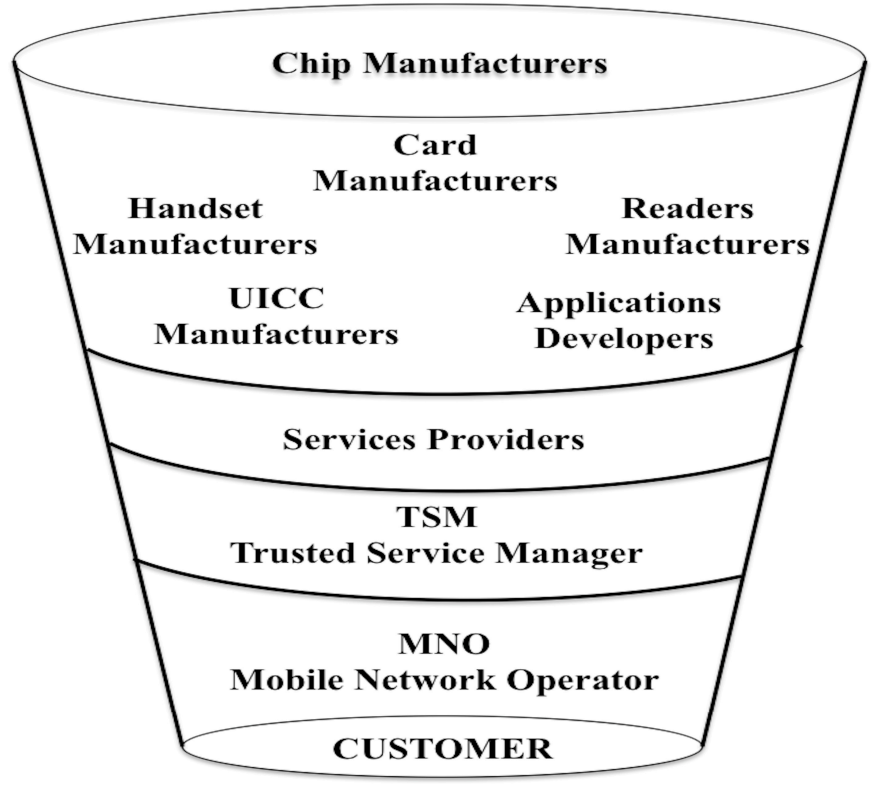

Technology in the mobile industry has been moving towards the integration of NFC technology in mobile commerce [10]. The driving force behind NFC is the public increasing dependence on smartphones and the demand for their functionality. This trend opened up many mobile commerce channels that will allow businesses to conduct a huge variety of transactions using NFC technology integrated on mobile devices. In light of these considerations, the many benefits and the potential uses of NFC technology that will continue to push innovations in the field are evident.

To understand the NFC technology trend, the Gartner Hype Cycle model is often used. It provides a graphic representation of the maturity, the adoption rate and the technologies dissemination timing and their applications [11]. Among the examined variables, this model includes the influences generated by the advertising campaigns and the interest rate of consumers [12]. The Hype Cycle curve supplements the information provided by the known S-curve [13] and the diffusion of the technology curve, which respectively identify the trend of evolution and the trade-off between technological change and market growth $[14,15]$.

Due to the Hype Cycle curve it is possible to understand the trend of future technologies by identifying economic activities, risks, opportunities and innovations that could be useful to CIOs (Chief Information Officer) in the business decision making process [16]. In particular, this curve allows for understanding which direction a technology is taking and how it is been seen by the market [17].

According to the Hype Cycle curve, Gartner, annually releases a report on the future technologies trends. The one released on August 2012 on the estimates for 2012 to 2013 places a greater focus on those technologies that can be used on a large scale. From the observations of the study, the state of Near Field Communication can be identified (Figure 2, [16]). It is now placed in the disillusionment phase, in which there is a decreasing rate of media interest. The plateau stage is expected to be reached in the next few years. As a matter of fact, the main infrastructure standards have been finalized and many mobile phone companies have also undertaken the market, by introducing improvements based 
on feedback collected following the trials carried out. Furthermore, a downward hype can be a sign of a delay to the diffusion of technology among users.

Figure 2. NFC technology in the Hype Cycle curve (source: authors' elaboration based on [16]).

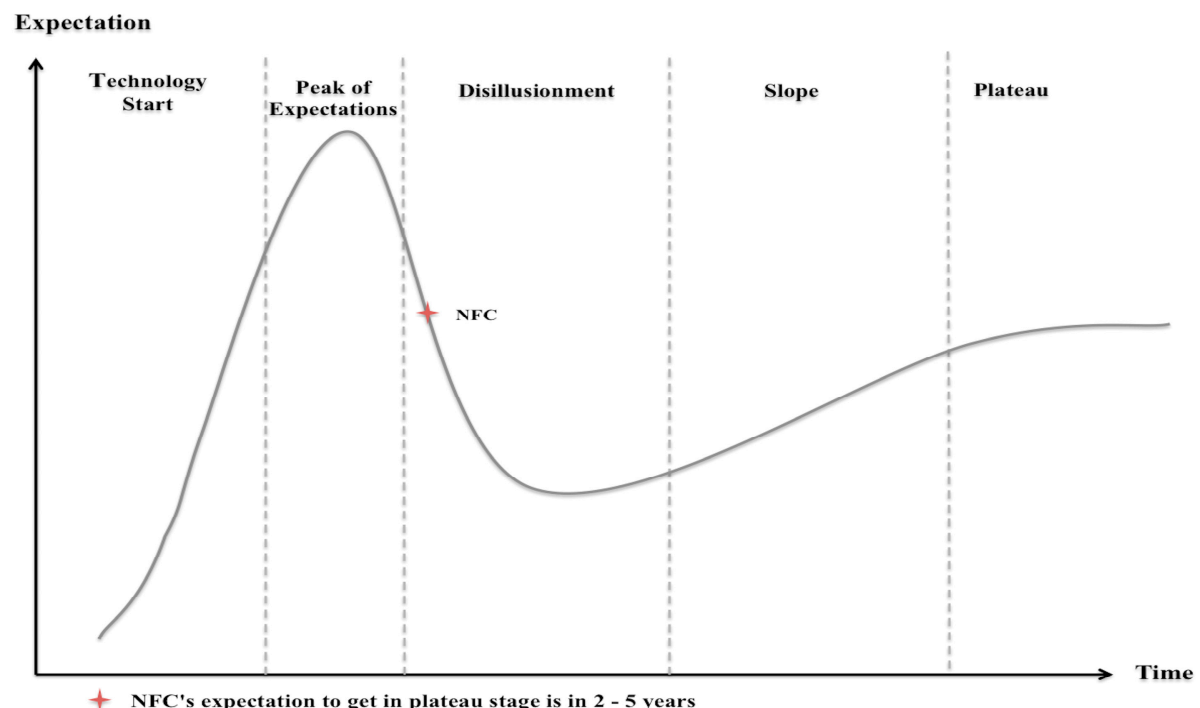

Mobile payment service markets are currently under transition, with a history of numerous tried and failed solutions, and a future of promising but still uncertain possibilities with potential new technology innovations. The main problem is to define NFC business model concerning its application to the payment markets, because those are markets characterized by heterogeneity, and therefore are comprised of many interactions. In fact, it is well known that to define the business model of any emerging technology can be very complex [18].

In particular, the hardest choice for the service providers is "how to" cooperate with other stakeholders to get into the market (Table 1, [19]).

Table 1. Three models on how service providers can cooperate with other stakeholders to get into the market (source: authors' elaboration based on [19]).

\begin{tabular}{ll}
\hline Model & Explanation \\
\hline Collaborative & $\begin{array}{l}\text { In a given state, stakeholders, providers of secure element, the MCPA SP } \\
\text { (Mobile Contactless Payment Application Service Provider) and other relevant } \\
\text { parties all together define an environment that allows every person to participate. }\end{array}$ \\
\hline Bilateral & $\begin{array}{l}\text { Within certain territorial limits, a provider of secure element and a developer of } \\
\text { contactless payment applications reach an agreement. }\end{array}$ \\
\hline Self-contained & $\begin{array}{l}\text { There is no collaboration. The application developer of the mobile contactless } \\
\text { payment and NFC secure element supplier are the same subject. }\end{array}$ \\
\hline
\end{tabular}


With reference to the model level, initially the NFC ecosystem was oriented more towards the self-contained model. With the feedback from trials and models adopted following some success stories, it has been decided to focus on the collaborative model, as this would facilitate the development of standards.

With the introduction of NFC technology, the potential contained in the smartphone has been exponentially growing due to its advantages, such as the simple and quick way of using this technology, the existence of compatible infrastructure around the world and the speed of connection establishment [20]. There are three main functions:

(1) Card emulation. allows the owner of the phone to use it as a tag for external readers, storing inside all the data related badges, payment cards, loyalty cards, access keys for the use of certain tools (e.g., printers), but also car keys, identity cards and health cards for public transport.

(2) Reader/writer mode. Is possible read or write external tags/smartcards such as those found on smart posters, download coupons directly on the device (ISO 14443)

(3) Peer-to-peer enables the exchange of data between devices (ISO 18092).

To highlight the main functions of NFC, Ok et al. [21] made an analysis, as shown in Table 2, which shows their benefits and future perspectives.

Table 2. Benefits and possible future perspectives NFC three main functions (source: authors' elaboration based on [20,21]).

\begin{tabular}{|c|c|c|c|}
\hline & ISO & Strengths & Future Perspective \\
\hline $\begin{array}{l}\text { Card } \\
\text { Emulator } \\
\text { Mode } \\
\end{array}$ & - 14443 & $\begin{array}{ll}\text { - } & \text { Contactless Payments } \\
\text { - } & \text { Data Storing } \\
\text { - } & \text { Access Control } \\
\end{array}$ & $\begin{array}{ll}\text { - } & \text { Integration of personal } \\
\text { ID-cards } \\
\text { - } \quad \text { Storage of sensible data }\end{array}$ \\
\hline $\begin{array}{l}\text { Reader/Writer } \\
\text { Mode }\end{array}$ & $\begin{array}{ll}\text { - } & 14443 \\
\text { - } & 15693\end{array}$ & $\begin{array}{l}\text { - Applicability in many } \\
\text { scenarios } \\
\text { - Marketing opportunity for } \\
\text { brands }\end{array}$ & $\begin{array}{l}\text { - Allow an higher } \\
\text { customization } \\
\text { - Increase the number of } \\
\text { possible scenarios }\end{array}$ \\
\hline $\begin{array}{l}\text { Peer-to-Peer } \\
\text { Mode }\end{array}$ & $\begin{array}{ll}\text { - } & 18092 \\
\text { - } & 21481\end{array}$ & $\begin{array}{l}\text { - Devices connection through } \\
\text { physical proximity } \\
\text { - Quick sharing of data } \\
\text { between devices }\end{array}$ & $\begin{array}{l}\text { - Secure share of } \\
\text { confidential/private } \\
\text { information }\end{array}$ \\
\hline
\end{tabular}

From the evidence, it appears that the spread of NFC technology has been rather slow, but the development time is needed to standardize the ecosystem and to make it interoperable [22].

The efforts of NFC ecosystem players in order to increase the rate of diffusion are driven by the idea that NFC could cover a significant role in the market of electronic payment systems, providing users with a wide range of benefits [2].

In order to have a clearer spectrum on Near Field Communication technologies, starting from the literature we made a SWOT Analysis to highlights strengths, opportunities, weaknesses and threats of NFC (Figure 3). 
Elizabeth Buse, of Visa's Global Executive Solutions Inc., during the NFC Mobile Money Summit in New York in October 2013, states that: "[the] NFC market is no longer a zero-sum as was thought until 5 years ago, full of winners or losers. Today, cooperation is needed to expand the ecosystem. You can apply to NFC the four rules applied to the credit card system 30 years ago to replicate its success, which are: business model for all stakeholders of the ecosystem; open technology; agreements on standards and involvement of regulatory authorities" [23].

From the regulatory point of view, the European legislator, in implementing the European Digital Agenda, recognized the existing impact of the NFC technology payment system. In addition to activities at the national and community level, the actions undertaken by the EPC have further strengthened the influence of normative commitment at European level.

Figure 3. NFC Technology SWOT Analysis (source: authors' elaboration).
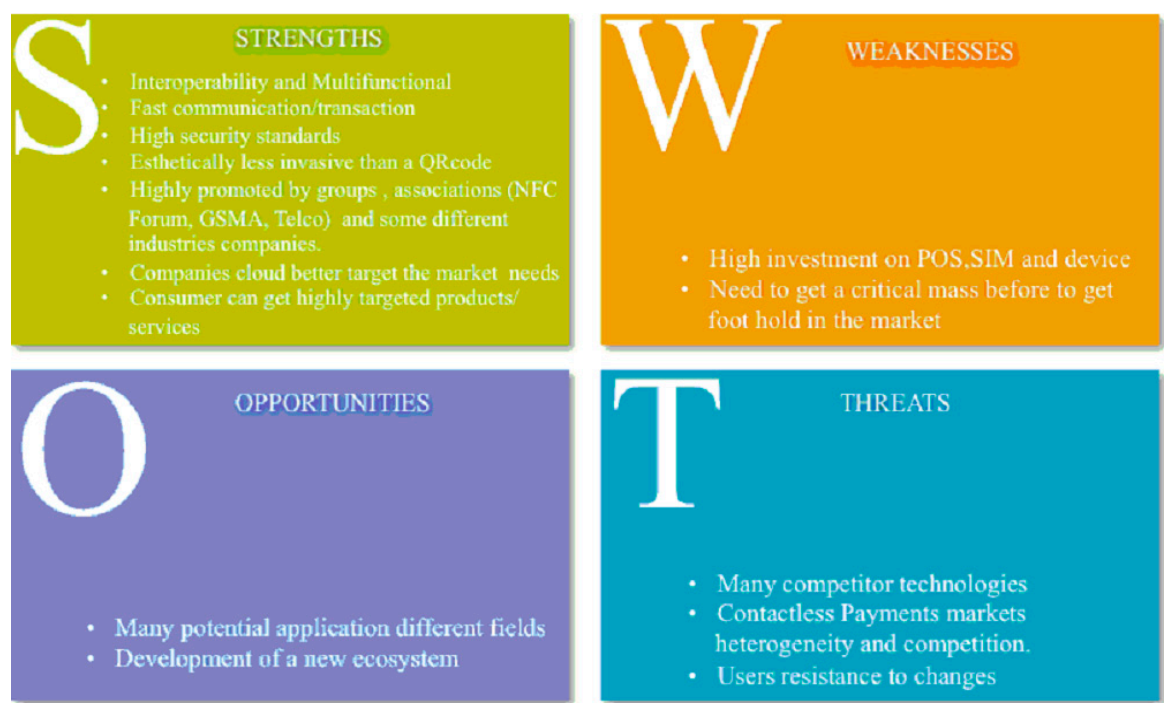

The guidelines for contactless transactions in the SEPA area (Single Euro Payments Area) are intended to accelerate the realization and the development of an NFC ecosystem [24]. In particular, the NFC main protocol is itemized by the ISO/IEC 18092 (ECMA 340) and some others important related standard are: ISO/IEC 21481 (ECMA 352); ISO/IEC 22536 (ECMA356); ISO/IEC 23917 (ECMA 362) and the ECMA 2005b (ECMA 373) [25].

"The new technologies and in particularly those related to the smartphones have been changing the telephony deeply. [...] The number of mobile phone in use far exceeds any other technical devices that could be used to market, sell, produce, or deliver products and services to consumers. These development open lucrative opportunities to merchants and service providers" [18].

Instead of the technologies that are already available in the market, NFC applied to payments introduces secure elements and stores the credentials for the payment on the device. There were several options potentially applicable before the GSMA (Group Special Mobile Association) opted for the adoption of NFC Subscriber Identity Module (SIM) [26]:

- SIM card: chip heart of all terminals GSM (Group Special Mobile) and is used as a security element for NFC payments. 
- Micro SD card: likewise safe, it has been proposed by the banks, but the number of trials conducted on the feasibility there have shown some technical problems including incompatibility with certain phones, difficulties with others and, first of all, it would be the most expensive option among the three alternatives, and the most difficult one.

- Embedded chip: chip set in the terminal, there is no need for the user to change or move anything. In the event that you want to change your phone, the data contained in the secure element terminal are transferred to the new phone OTA (over the air).

As a matter of fact, the GSMA (Group Special Mobile Association) decided to adopt NFC SIM, allowing for the standardization of NFC technology. This standardization does not provide a model focused on the dominant role of a subject (e.g., MNO-Mobile Network Operator —or banks), but it suggests that the impact of standardization is accomplished thanks to all players in the market $[27,28]$. Its extending domination through vertical enablers (such as banks, operators and actors over the top "OTT") is able to drive bottom-line benefits for a range of vertical markets [29].

The key factors of this scenario are centered on the large standardization and on the uniformed adoption of NFC SIM. The basic conditions assumed for this scenario are:

- The complete standardization of NFC SIM, obtained with the adoption of infrastructures and protocols by all the actors in the ecosystem.

- The collaboration is focused only on the technological standard; it doesn't assume any collaboration on the go-to-market strategies, assets structure or joint investments.

- The MNO manages the secure element.

- The financial impact on the collaboration and standardization is limited to economies of scale.

- The main impact on the ecosystem is driven by the cost reduction and the effects of the network for key stakeholders in the private sector, as well as externalities and low barriers to entry.

- The consumer experience is defined interoperable inter-sector and inter-product.

The use of the SIM, otherwise known as the UICC (Universal Integrated Circuit Card), can be divided into security domains that allow service providers of third parts to manage and operate the services they provide, regardless of the mobile operators. The SIM card securely stores the identity of the holder and over the years has become more and more sophisticated, increasing the power of data processing, memory, and security management. This therefore provides an ideal environment in which to install an application, Pay-by-Mobile, which dematerialized a debit card or credit a card, and allows the user to use a phone as a wallet, counting on the SIM card as an element of security for transactions. In particular, the applications on the SIM card can be easily updated by mobile operators and be moved from one device to another [30].

The mobile network operators (MNO) and the Service Provider are equipping themselves with TSM platforms (Trusted Service Manager) [31], as the TSM is a neutral intermediary that controls the secure element and contact all relevant stakeholders (companies, banks, handset manufacturers and customers), enabling them to access remote data to a remote management application [32].

TSM was developed to overcome the issue of how to create an interoperable mobile NFC ecosystem that makes easier for Service Providers (SP) and MNOs to work together [29]. It acts as the link between the SPs and MNOs worlds from a technical perspective, ensuring also a level of trust and confidentiality between the actors: 
- Providing the single point of contact for the Service Providers to access their customer base through the MNOs.

- Managing the secure download and life-cycle management of the Mobile NFC application on behalf of the Service Providers [33].

The role of TSM can be explained through three different models, as illustrated in Table 3, each of which enables different responsibilities among the parties according to the different modes of SP's applets management.

Table 3. Three management modes of service provider applets (source: authors' elaboration based on [29,34]).

\begin{tabular}{|c|c|c|c|}
\hline & Simple Mode & Delegated Mode & Dual Mode \\
\hline $\begin{array}{l}\text { Applets } \\
\text { Management }\end{array}$ & $\begin{array}{l}\text { SP delegates full } \\
\text { management of its } \\
\text { application to MNO. }\end{array}$ & $\begin{array}{l}\text { SP can delegate card content } \\
\text { management to TSM but each } \\
\text { operation requires MNO's } \\
\text { preauthorization } \\
\text { (in the form of a token). }\end{array}$ & $\begin{array}{l}\text { Performed by both MNO } \\
\text { TSM and SP TSM. }\end{array}$ \\
\hline \multirow[t]{2}{*}{$\begin{array}{l}\text { Card Content } \\
\text { Management } \\
\text { and Security } \\
\text { Responsibilities }\end{array}$} & $\begin{array}{l}\text { MNO TSM performs the } \\
\text { CCM and is responsible } \\
\text { for both security domain } \\
\text { management and secure } \\
\text { element management. }\end{array}$ & $\begin{array}{l}\text { MNO is still responsible for } \\
\text { security domain management } \\
\text { (allocating the space } \\
\text { in the UICC). }\end{array}$ & $\begin{array}{l}\text { Both have reserved } \\
\text { domains allocated } \\
\text { in the secure element. }\end{array}$ \\
\hline & $\begin{array}{l}\text { SP TSM can monitor } \\
\text { MNO TSM. }\end{array}$ & $\begin{array}{l}\text { SP TSM is responsible for the } \\
\text { secure element management. }\end{array}$ & $\begin{array}{l}\text { The secure element must } \\
\text { have at least two security } \\
\text { domains. }\end{array}$ \\
\hline Data & $\begin{array}{l}\text { SP is responsible of the } \\
\text { data personalization of } \\
\text { its applet through } \\
\text { MNO TSM. }\end{array}$ & $\begin{array}{l}\text { SP TSM can install the secure } \\
\text { element applet directly or } \\
\text { through the MNO TSM, } \\
\text { gaining access using the token. }\end{array}$ & $\begin{array}{l}\text { The MNO is able to offer } \\
\text { specific space for the SP's } \\
\text { secure domain based on the } \\
\text { rules to manage the memory } \\
\text { allocated for a secure } \\
\text { domain specified by } \\
\text { GlobalPlatform. }\end{array}$ \\
\hline Miscellaneous & $\begin{array}{l}\text { For EMV (Europay, } \\
\text { MasterCard, Visa) } \\
\text { payment applet, the } \\
\text { MNO TSM might be } \\
\text { EMV certified. }\end{array}$ & & $\begin{array}{l}\text { Card content management is } \\
\text { fully delegated to a TSM for } \\
\text { a sub area of the UICC. } \\
\text { Several entities are } \\
\text { authorized to perform CCM. }\end{array}$ \\
\hline
\end{tabular}

These models cover application loading and personalization processes on UICC based SEs, which deploy NFC services [32].

Using over-the-air (OTA) channels and thanks to the connectivity provided by MNO, TSM can manage:

- Security domains' Life Cycle on the secure element in order to provide secured blocks of space for services.

- Applets' Life Cycle on the security domain of a secure element. 
- The update of the secure element with to make it work on newer devices.

- The recovery mechanisms to the MNO and Service Provider utilizing the service in case of outages.

- The reporting to each service provider on the amount of space used and the number of services running.

Therefore, the TSM infrastructure can be defined as an OTA personalization system for secure element applets and a generic life-cycle manager of the provisioned applets [34].

Even manufacturers of mobile terminals and Point of Sale (hereinafter will be referred to by the acronym POS) are supporting the adoption and the deployment of NFC technology.

Recently, new form of POS emerged in the market, well responding to SMEs needs to deliver payment services. Equipping smartphones and/or tablets with a secure card reader, they can be turned into Mobile POS [25]. Some examples are Square, iZettle, Payleven and Jusp. The related business model is based on the same scheme for all the companies: low percentage fee per transaction and sometimes a set-up fee for the hardware, granting high flexibility to the merchant and new ways to engage the unserved small business segment customer [35].

The major device manufacturers such as Samsung, RIM and Microsoft Mobile Oyj (formerly Nokia) are launching a wide range of NFC phones that support the approach advocated by the GSMA. According to the estimates of the association, nearly 1.5 billion SIM-based NFC phones will be sold between 2010 and 2016, with a turnover estimated at about 50 billion dollars, according to predictions based on industry research conducted by firm Strategy Analytics. In addition, according to ABI Research, by 2016 the $85 \%$ of the terminal points of sale will be sent to NFC [25].

\section{NFC Mobile Payment}

Together with the evolution of the devices, the habits of the users have also evolved. Thanks to smartphones, the "mobile payment" has spread this paradigm, which is changing the landscape of payments significantly, allowing users to run them anytime, anywhere (Figure 4). "The mobile payments are payments for goods, services, and bills with a mobile device by taking advantage of wireless and other communication technology". [...] "The main players in the market for mobile payments are mobile payment service providers and their clients" [18].

There are two different kinds of mobile payment: remote mobile payment and mobile proximity payment. Remote mobile payment is when the dealer activates the payment remotely, allowing the customer to complete the purchase through different ways such as text message, website, by referring to a bar code scanned by the operator, reading QR codes, call to IVR (auto responder) and applications installed on the device. Mobile proximity payment consists in bringing the own device to an NFC- enabled POS to make the payment.

Another division of the mobile payment concerns how it is possible to make the payment. In this case, there are "two categories: payments for daily purchases, and payments of bills. For purchases, and complement or compete with cash, credit cards, and debit cards. For bills, mobile payments typically provide access to account-based payment instruments such as money transfers, internet banking payments, direct debit assignments, or electronic invoice acceptance" [18]. 
Figure 4. Payment process through NFC smartphones applets (source: authors' elaboration based on [36]).

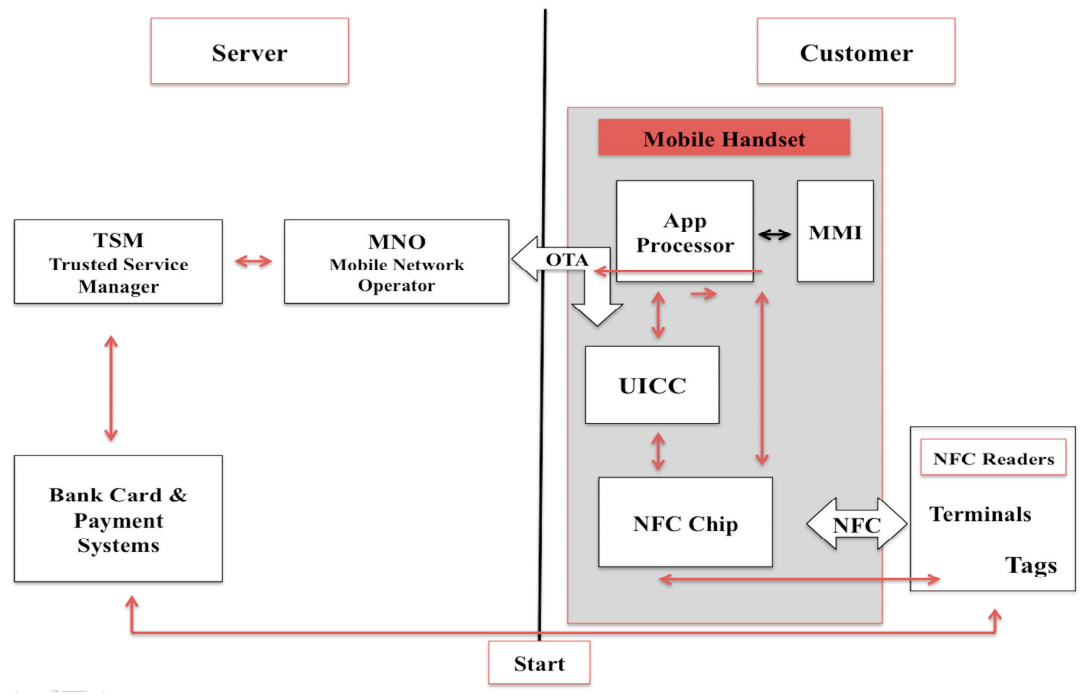

With the increasing diffusion rate of smartphones, NFC and the expansion of NFC POS all over the world, the percentage of people that use NFC and mobile wallet services has been growing over time [37]. For example, in Italy this percentage is around 3\% [38].

As we can observe in the Figure 5, in all markets the spread of NFC technology is driven by many factors.

Figure 5. Example of some of the main NFC technology factors (authors' elaboration).

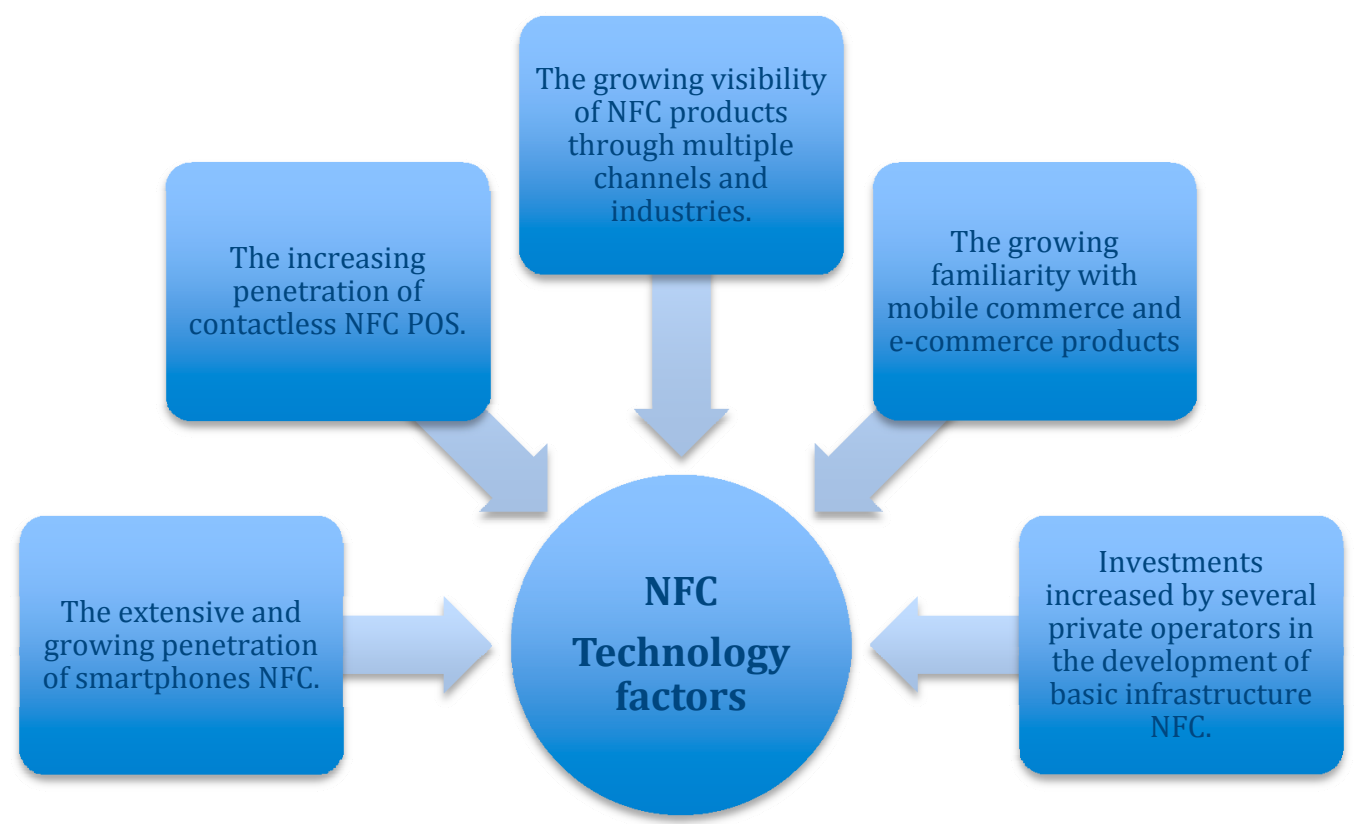

Linked to the volume of adoption there is technological standardization. From the general scenario it emerges that the greatest impact of technology standardization corresponds to an equal increase in transactions. This hypothesis is analyzed by the Working Group of the GSMA, and has defined the projections on market trends and on specific benchmarks of the industry [39]. 
According to this model, it is assumed that the replacement rate of infrastructure NFC-enabled in all vertical markets will be higher, thanks to the commercial benefits of the standardization [39]. These benefits affect the adoption rate of NFC terminals such as POS, turnstiles in public transport systems and ticket machines. In addition, the model predicts higher rates of diffusion and utilization, partly arisen by the acceleration in the implementation of the fundamental components of the ecosystem made by vertical enablers [40].

Despite the basis for the distribution of NFC are rising in all the markets; developments show that the adoption of this technology is directly related to the prevalence of compatible infrastructures and the degree of knowledge of the product in the market. Although several initiatives have been taken, the lack on the adoption of a high volume of infrastructures could inhibit the perceived usefulness of NFC products, limiting the awareness of them in the market.

According to data published by NFC and Mobile Payments at the Polytechnic University of Milan [41], in 2013 contactless NFC POS terminals should exceed 170,000 units, against the 30,000 at the end of 2012 and the 5000 of 2011 . Whereas at the end of 2012, the number of NFC smartphones owned in Italy amounted to 2.5 million; the increase in adoption rates is noticeable, but it is still far from achieving the critical mass (tipping point).

The results of the mobile payment in 2013 were presented in a report published by the GSMA. According to the report, mobile devices enabled for tap-and-go, or payment through NFC technology, are beginning to achieve wide penetration, in fact, in 2012 one out of four of the smartphones that have been delivered were endowed of NFC technology [30].

In Europe, the technology of the mobile proximity payment has been available since early 2011 and by 2017 , it is estimated that $25 \%$ of the phones in the United States and Western Europe will make payments in stores [42].

\subsection{The International Trend}

The complexity of the ecosystem and the number of stakeholders involved leads to a discrete initial progress in the rollout of NFC technology. The pace of services for SIM-based NFC smartphones is growing rapidly thanks to the increasing number of mobile enabled. It is driven mainly by trial and experiments carried out by mobile operators and banks.

ABI Research estimates that in 2013 approximately 200 million NFC phones have been sold globally and NFC transaction value of mobile payments will increase, going from 4 billion dollars of 2012 to 191 billion dollars in 2017 [43].

Near Field Communication as a means of payment is becoming more and more known among consumers thanks to the success of the pilot tests. In May 2012, Juniper Research published a report according to which global NFC payments will exceed 180 billion dollars by 2017 .

Some of these trials have been launched on a small scale, focusing on cities that are considered strategic. This is the case of the joint venture ISIS, promoted by three mobile operators in the U.S. (AT\&T, T-Mobile and Verizon Wireless), which have made experiments in the cities of Austin, Texas and Salt Lake City, Utah, providing a mobile wallet on which customers could upload their debit or credit card. They could choose among 40 compatible ISIS smartphone models. On 14 November 2013 instead of using the information collected during the trial, the commercial launch of mobile proximity 
payment service across the territory of the Member States took place, with the possibility to use also special offers and discounts in collaboration with partners such as American Express, Jamba Juice and Coca-Cola [44].

Following the trials carried out by Telco and banks, they are ready to begin the commercial launch. Some examples besides the above-mentioned ISIS in the U.S., there are LaCaixa (Spanish bank), ready to a national roll-out scheduled for February 2014 in collaboration with Telefónica, Vodafone and Orange, which together constitute $80 \%$ of the telecommunications market in Spain, and NTT DoCoMo ready for a worldwide service use. The Japanese Telco, following the agreement signed with MasterCard in October 2012, has been able to develop for its clients the chance to pay all over the world through a NFC smartphone to merchants who have MasterCard PayPass POS.

The market is characterized by several, potentially competing, technologies such as biometric authentication for validation of payments and the HCE (Hosting Card Emulator), that is, the ability to download data directly from the cloud of a payment card. These solutions are likely to increase consumer confidence in the use of mobile payment, because both can be integrated in smartphones. Besides of this, HCE also requires the NFC interface to communicate with the merchant's POS in order to close the transaction [45].

\subsection{Current and Future Trends}

"NFC technology is considered the mainstream technology of the next generation for the mobile phone products" [25].

Several contactless services are already exploited by smartphones and soon new ones will be developed, such as: verifying the authenticity of a product, receiving detailed information on the composition and maturity of foodstuffs, buying tickets for matches or concerts directly from the smart poster, the spread of electronic meal vouchers, access to the hotel room lock through NFC. In addition, the car rental might be done through an online booking and confirmation through the smartphone containing the key [46]. Among other contactless services you can also find: visits to museums, parks and other places of interest, greater involvement in trade shows and events, as well as check-in at the airport, the exchange of business cards or the optimization of waste management.

\section{Tourism Value Chain and NFC}

According to Buhalis and Law [47], among the ICT (Information and Communication Technologies), tourism is one of the most meaningful industries. Several ICT developments are not meant directly for tourism, but they are able to generate a strong impact on it. Travelers are using phones, tablets and the related apps before, during and after the trip [48]. Wang et al. [49] state that the tourist experience can be strongly affected by mobile phones. In support of this idea, Ricci also highlighted that smartphones are becoming important instruments to get information and therefore tourism mobile applications [50]. According to Pesonen and Horster [51], "NFC technology can be regarded as one of the recent ICT developments that has a huge potential for travel and tourism". As it is shown in the literature it is very important to be able to manage this topic which is developing continuously by making the topic significant in the tourism management perspective. 
Even though the literature exploration of NFC application in the tourism industry is not that big yet [52], this technology has several uses within tourism value chain. Madlmayr and Scharinger, in 2010 [51,53] tried to gather these uses in three macro categories: information systems, workforce management and location-based services. Most recently, Egger [52] identified ten main functionalities of NFC applicable in tourism. They are: mobile payment, information supply, access authorization, network access, management of loyalty, bonus and membership cards, mobile ticketing, workforce management, identification and location of base services.

Starting from the evidence highlighted in the literature, in this part of our research work we focused the scientific exploration on NFC applications related to the macro areas of the tourism value chain (Figure 6). Therefore, the main objective was to see how NFC technologies could be related to the tourism value chain (TVC) prospect, published by DEVCO and UNWTO [54] in 2013, to improve the planned elements and/or those that have been developing, as it is shown in the figure below (Figure 6). To pursue this objective, we tried to map some selected examples of NFC applications linking each of them to a specific stage of the tourism value chain. In this way, it was possible both to get more concrete evidence on the opportunities offered by the applications of this technology in a managerial perspective and see the trend on which it has been orienting its development in the last few years.

Figure 6. TVC -Tourism Value Chain (source: authors' elaboration based on [54]).

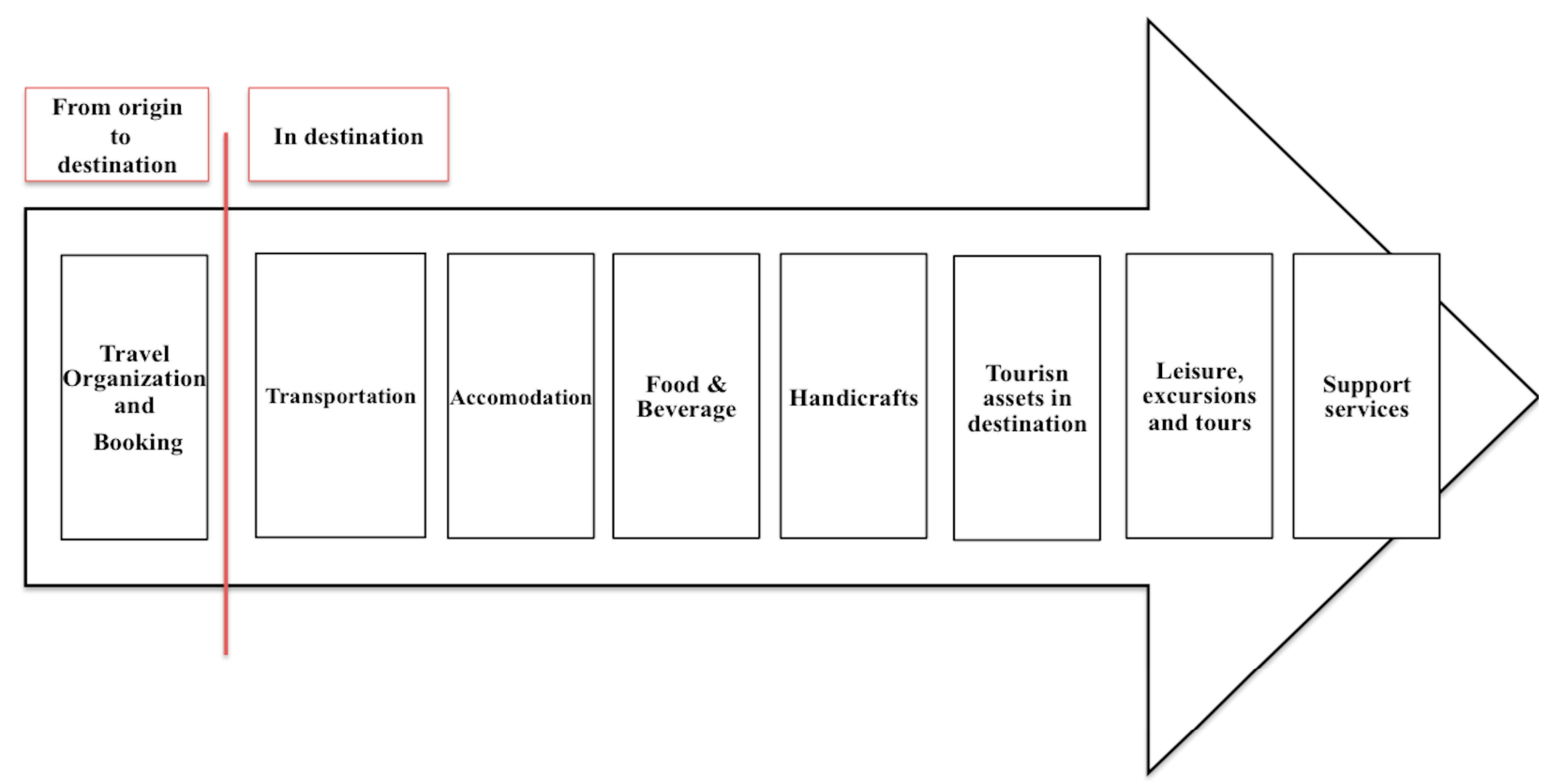

Looking at the NFC applications related to the TVC stages, we can find:

- Travel organization and booking:

The travel organization and booking stage includes all the steps of the trip settings, from the origins to the destination. One of the main NFC applications is related to the air-transport industry. In fact, in the White Paper done by GSMA and IATA "six different use cases have been defined where mobile NFC can bring great benefits to the airlines, airport authorities and the air-traveler, namely: Passenger check-in, Baggage check-in, Security check-point, Lounge access, Boarding, Post-flight" [55]. A direct example of that mentioned by Clark [52,56] 
concerns Scandinavian Airlines (SAS), which gives SmartPass stickers to Scandinavian Euro Bonus Gold frequent flyers in order to give them a check-in and boarding process that is easier and faster.

- Transportation:

The main highlighted NFC applications linked to the transportation stage are those related to bus and taxi services. For example, recently in London, the London's Radio Taxi operator built a huge marketing operation "by placing NFC and QR code stickers in its 2500 vehicles". In this way [...] "Scanning or tapping the stickers provides passengers with a direct link to the company's app, which they can then use to call the nearest Radio Taxi with one click as well as see the taxi's location in real time". According to Phil Coote, CEO of the company (RapidNFC) that had an important part in the creation of the Radio Taxi stickers, Radio Taxi have significantly increased the number of passengers, thanks to this marketing strategy [57].

Concerning bus service, in Rio de Janeiro 5000 NFC and QR code stickers have been placed to provide information on bus time and routes. Those five thousand stickers are part of a bigger project "Rio Smart City" that allow users to get information also to local tourist destination, events and point of interests [58].

- Accommodation:

In 2010, the Clarion Hotel in Stockholm, according to Clark [59], by using the RFID installed base locking systems infrastructure, offered the possibility for its customers to receive the room key on their NFC smartphone, skipping (or reducing the time for) the check-in and going directly to their room [60]. Most recently, the Aimia Hotel, part of the resort of Port de Soller, in Mallorca, has placed a panel with NFC tag $\mathrm{d}$ in the reception's area of the hotel, and guests, by tipping on it, can access different information, from those linked to the hotel like the restaurant menu or the hotel's WIFI password, to those related to local services like weather forecasts, places of interest and public transportation [61].

- Food and beverage:

Ho and Chen [62] explained nonetheless in their work how NFC may impact both the user experience and satisfaction, i.e., in a restaurant, through NFC devices, customers could receive personalized menus, without foods they don't eat. In light of that, Argueta et al. developed a mobile application, NapkiNotes, that exploiting NFC technology "allows users to select dishes from a menu [...], filter food selection based on ingredient, submit the order, and be alerted when the food is ready". In fact, placing a sticker with NFC tag at each dining table the restaurant staff can easily find who made the order [63].

- Handicrafts:

Concerning some of the main NFC applications, more useful in TVC, linked to the handicrafts stage is it possible to associate: the shop in store, save offers and send money $[64,65]$. In this way, an example of a service that include all these features (and others) is the Google wallet. In fact, the 2.3 version include different features like: 
○ Shop in store: Users with mobile phone NFC enabled devices can make contactless purchases in stores. This features makes the tourist's (and users in general) shopping more attractive by facilitating it.

○ Save offers: Users could be able to store a huge numbers of offers in Google Wallet, regardless where the users have found the offer. This feature cloud be useful for a tourist (or a user in general) who might have saved offers on some couponing websites (for example: Valpak).

○ Send money: With this service users can send money, by the app, to anyone in the United States who has an email account $[64,65]$.

\section{- Tourism assets in destination:}

Another evidence of how to implement this technology in the tourism is reported by Clark [66], in the London Museum through NFC tags additional information has been provided about the objects and also there were tags for Facebook Check-Ins, and others to share contents on social network like Facebook or Twitter, to improve the customer's loyalty. A similar experience was set up in Wolfsoniana Museum in Genoa: according to Ceipidor et al. [67], they explained that through a mobile app which can use both NFC and QR technology, it was possible to enhance the visiting experience of the customers, delivering additional user-adjustable contents during the visit, like multimedia and interactive with innovative tools, transforming the Wolfsoniana in a Smart Museum.

- Leisure, excursions and tours:

An interesting example of NFC application in the TVC is the one reported by Clark [68] concerning an interactive walking tour exploiting NFC tags and QR codes In fact, the New South Wales Government has supported the development of an interactive walking tour of The Rocks, the oldest district of Sydney. Visitors by tipping or scanning the NFC tag and QR codes will have the access to an interactive self-guided tours.

- Support services:

According to Pesonen and Horster [51], Lindsey [69] presented the mobile application EpicMix, designed to be used in ski resorts. In fact, the application was launched in fall 2010, in Vail Resorts in Colorado; Resorts have been equipped with RFID scanners in order to offer to "the users the ability to track physical accomplishments and share the skiing experiences within social networks". Another interesting example of NFC application linked to support services is the "Shibuya Clickable Project" in Tokyo. In fact, Shibuya is one of Tokyo's busiest shopping districts. The firsts 300 streets of the area have been equipped NFC tag stickers, which allows users, by tapping the NFC tag, to get information and advertising services. For the future are planned some developments of the "Shibuya Clickable Project" like: emergency and civil disaster information, the chance to get involved in a treasure hunt game as well as an information service for international tourists [70].

As is it shown in the case analyses above, NFC technologies applied to the tourism industry can enrich and facilitate tourist travels experiences. In addition, companies can get more targeted 
information on the customers' behaviors in order to be able to release products and/or services that would answer to market needs.

\section{Conclusions}

As we could see in the Hype Cycle curve, NFC technology is in the disillusionment stage. As we highlighted in this research work, there is the matter of fact that the main infrastructure standards have been finalized and many mobile phone companies have also undertaken the market. Furthermore, a downward hype can be a sign of a delay on the diffusion of technology among users.

As it is highlighted in the SWOT analysis, NFC technology has lots of strengths as well as some opportunities, but there are also some weakness and threats.

Mobile payment service markets are currently under transition, with a history of numerous tried and failed solutions, and a future of promising but still uncertain possibilities with potential new technology innovations. Even the acceptance of NFC is mostly dependent on payment systems. However, there are also new competitors coming up such as payment through fingerprints and facial recognition. In fact, it is well known that the payment markets are characterized by high heterogeneity and high competition. Finally, the customer's resistance to change could represent the main or at least one of the main threats for the diffusion of NFC technology.

Among the strengths of NFC technology we can highlight that companies can easily reach the consumers. Therefore, on one hand, companies can get from consumers behaviors, geo-localized and precise information about their habits, in order to provide more and more-targeted services and/or products based on the market demands; on the other hand, consumers can get targeted products and/or services that would answer their needs. A proof of that comes from what has emerged from the analysis of the tourism industry. In addition, especially from the findings related to the association of some example of NFC applications at each stage of the tourism value chain.

NFC technology has lots of strengths and opportunities that can facilitate and satisfy the user experience for customers in many other different industries beyond the tourism industry. One of the main challenges for the dissemination of NFC technology is to be able to overcome the potential consumer's resistance to change. However, this could be seen only with time and with future research [51].

\section{Author Contributions}

This review was conducted equally by all the authors, which have read and approved the final manuscript.

\section{Conflicts of Interest}

The authors declare no conflict of interest.

\section{References}

1. NFC Forum, www.nfc-forum.org. Available online: http://www.nfc-forum.org/resources/ faqs\#howwork (accessed on 29 April 2014).

2. Ortiz, S., Jr. Is near-field communication close to success? Computer 2006, 39, 18-20. 
3. Yaqub-Undergraduate, M.U.; Shaikh-Undergraduate, U.A. Near Field Communication-Its Applications and Implementation in K.S.A. 2012. Available online: http://www4.kfupm.edu.sa/ ssc/4845_MohammedUmair_Yaqub.pdf (accessed on 29 April 2014).

4. Talone, P.; Russo, G. RFID. Fondamenti di una Tecnologia Silenziosamente Pervasiva; Fondazione Ugo Bordoni: Rome, Italy, 2008.

5. Zimmerman, T.G. Personal area networks: Near-field intrabody communication. IBM Syst. J. 1996, 35, 609-617.

6. Want, R. Smartphone. IEEE Pervasive Comput. 2011, 10, 4-7. Available online: http://www.sicherungssysteme.net/fileadmin/NFC_Pervasive_Computing_July-Sept2011.pdf (accessed on 29 April 2014).

7. Haselsteiner, E.; Breitfuß, K. Security in near field communication (NFC). In Proceedings of the Workshop on RFID Security, Graz, Austria, 12-14 July 2006; pp. 12-14.

8. Madlmayr, G.; Langer, J.; Scharinger, J. Managing an NFC ecosystem. In Proceedings of the 7th International Conference on Mobile Business, 2008 (ICMB '08), Barcelona, Spain, 7-8 July 2008; pp. 95-101.

9. Agrawal, P.; Bhuraria, S. Near Field Communication. SETLabs Breifings 2012, 10, 67-74.

10. Du, H. NFC technology: Today and tomorrow. Int. J. Future Comput. Commun. 2013, 2, 351-354.

11. Fenn, J. Hype Cycle for Emerging Technologies, 2010. Gartner Research. Available online: http://www.chinnovate.com/wp-content/uploads/2011/09/Hype-Cycle-for-Emerging-Technologies2010.pdf (accessed on 29 April 2014).

12. Linden, A.; Fenn, J. Understanding Gartner's Hype Cycles; Strategic Analysis Report N R-20-1971; Gartner Inc.: Stamford, CT, USA, 2003.

13. Schilling, M.A.; Esmundo, M. Technology S-curves in renewable energy alternatives: Analysis and implications for industry and government. Energy Policy 2009, 37, 1767-1781.

14. Lucchetti, M.C.; Arcese, G. Innovazione. In Tecnologia \& Produzione, 2nd ed.; Chiacchierini, E., Ed.; CEDAM: Padua, Italy, 2012; pp. 99-152.

15. Arcese, G.; Flammini, S.; Martucci, O. Dall'Innovazione alla Startup - L'esperienza d'imprenditori italiani in Italia e in California, 1st ed.; McGraw-Hill: Milan, Italy, 2013.

16. Pettey, C.; van der Meulen, R. Gartner's 2012. Hype Cycle for Emerging Technologies Identifies "Tipping Point" Technologies That Will Unlock Long-Awaited Technology Scenarios; Gartner Inc.: Stamford, CT, USA, 2012.

17. Fenn, J.; Raskino, M. Mastering the Hype Cycle: How to Choose the Right Innovation at the Right Time; Harvard Business Press: Boston, MA, USA, 2008.

18. Dahlberg, T.; Mallat, N.; Ondrus, J.; Zmijewska, A. Past, present and future of mobile payments research: A literature review. Electron. Commer. Res. Appl. 2008, 7, 165-181.

19. Mobey Forum. White Paper Business Models for NFC Payments. 2011. Available online: http://www.sicherungssysteme.net/fileadmin/Mobey_Forum_White_Paper_Business_models_ for_NFC_payments.pdf (accessed on 29 April 2014). 
20. Falke, O.; Rukzio, E.; Dietz, U.; Holleis, P.; Schmidt, A. Mobile Services for Near Field Communication; Tech. Rep., LMU-MI-2007-1; University of Munich, Department of Computer Science, Media Informatics Group: Munich, Germany, 2007. Available online: http://www.mmi.ifi.lmu.de/pubdb/publications/pub/falke2007mobileServicesTR/falke2007mobile ServicesTR.pdf (accessed on 29 April 2014).

21. Ok, K.; Coskun, V.; Aydin, M.N.; Ozdenizci, B. Current benefits and future directions of NFC services. In Proceedings of the 2010 International Conference on Education and Management Technology (ICEMT), Cairo, Egypt, 2-4 November 2010; pp. 334-338.

22. Moscoso, O.Z.; Lekse, D.; Smith, A.; Holstein, L. Understanding the current state of the NFC payment ecosystem: A graphbased analysis of market players and their relations. Enfoque UTE 2012, 3, 13-32.

23. NFC Mobile Money Summit. Visa Follow Four Rules Reproduce Age Plastic. 2013. Available online: http://www.mobileworldlive.com/visa-follow-four-rules-reproduce-age-plastic (accessed on 29 April 2014).

24. European Payments Council. Available online: http://www.europeanpaymentscouncil.eu/ content.cfm?page=sepa_vision_and_goals (accessed on 29 April 2014).

25. Wu, S.H.; Yang, C. A study on designing the new near field communication technology-NFC-micro SD Technology. Inf. Technol. J. 2013, 13, 1455-1458.

26. Edgar, Dunn \& Company (EDC). Advanced Payments Report 2012. 2012. Available online: http://www.edgardunn.com/press/issues-and-opportunities/93-2012-advanced-payments-report (accessed on 29 April 2014).

27. Liu, Y.; Kostakos, V.; Deng, S. Risks of using NFC mobile payment: Investigating the moderating effect of demographic attributes. In Proceedings of the 15th International Conference on Electronic Commerce, Turku, Finland, 13-15 August 2013; pp. 125-134.

28. Mahajan, V.; Muller, E.; Bass, F.M. New product diffusion models in marketing: A review and directions for research. J. Market. 1990, 54, 1-26.

29. Global Platform. Global Platform's Proposition for NFC Mobile: Secure Element Management and Messaging. White Paper, 2009. Available online: http:/www.globalplatform.org/documents/ GlobalPlatform_NFC_Mobile_White_Paper.pdf (accessed on 29 April 2014).

30. GSMA. NFC-The Technology. 2013. Available online: http://www.gsma.com/mobilenfc/nfcthe-technology (accessed on 29 April 2014).

31. Easley, D.; Kleinberg, J. Networks, Crowds, and Markets; Cambridge University Press: Cambridge, UK, 2010; Volume 8.

32. EPC (European Payment Council)_GSMA. Trusted Service Manager, Service Management Requirements and Specifications. 2010. Available online: http:/www.gsma.com/digitalcommerce/ epc-gsma-trusted-service-manager-service-management-requirements-and-specifications-january2010 (accessed on 29 April 2014).

33. Corda, A.; Bobo, L.; Azoulai, J. U.S. Patent Application 12/679,874, 2008. Available online: http://www.google.com/patents/US20100205432 (accessed on 20 June 2014).

34. GSMA. The Role of the Trusted Service Manager in Mobile Commerce, December 2013. Available online: http://www.gsma.com/digitalcommerce/wp-content/uploads/2013/12/GSMATSM-White-Paper-FINAL-DEC-2013.pdf (accessed on 22 June 2014). 
35. Mobey Forum. The MPOS Impact: Shifting the Balance of Power, November 2013. Available online: http://www.mobeyforum.org/w/wp-content/uploads/Mobey-Forum-Whitepaper_TheMPOS-Impact.pdf (accessed on 22 June 2014).

36. Warakagoda, N. Near Field Communication (NFC) Opportunities \& Standards. Available online: http://www.umts.no/files/081028\%20nfc_standards_payments\%20Narada.pdf (accessed on 29 April 2014).

37. Mulliner, C. Vulnerability analysis and attacks on NFC-enabled mobile phones. In Proceedings of the International Conference on Availability, Reliability and Security (ARES '09), Fukuoka, Japan, 16-19 March 2009; pp. 695-700.

38. Neilsen Report. The Mobile Consumer-A Global Snapshot. 2013. Available online: http://www.nielseninsights.it/wpcontent/uploads/2013/03/03.global_mobile_report_02_25.pdf (accessed on 29 April 2014).

39. GSMA. Socio-Economic Benefits of SIM-Based NFC. 2011. Available online: http://www.booz.com/ media/file/GSMA-Booz-Study_Socio-economic-benefits-of-SIM-based-NFC.pdf (accessed on 29 April 2014).

40. Acker, O.; Knott, M.; Marcelis, Y. Socio-Economic Benefits of SIM-Based NFC. GSMA, 2011. Available online: http://www.gsma.com/digitalcommerce/wp-content/uploads/2012/03/ gsmaboozstudysocioeconomicbenefitsofsimbasednfc1.pdf (accessed on 29 April 2014).

41. Osservatorio NFC \& Mobile Payment. Mobile Payment: l'Italia s'è desta! 2013. Available online: http://www.osservatori.net/c/document_library/get_file?folderId=1241114\&name=DLFE22128.pdf (accessed on 29 April 2014).

42. Juniper Research. NFC Mobile Payments \& Retail Marketing-Business Models \& Forecasts 2012-2017. 2012. Available online: http://www.juniperresearch.com/viewpressrelease.php?pr=315 (accessed on 29 April 2014).

43. ABI Research. ABI: NFC Payments to Hit $\$ 100$ bn; ABI Research: New York, NY, USA, 2012.

44. Clark, S. Isis NFC Mobile Wallet Goes Live across the US. 2013. Available online: http://www.nfcworld.com/2013/11/14/326846/isis-nfc-mobile-wallet-goes-live-across-us/ (accessed on 29 April 2014).

45. Pyments.com. UL: HCE Can Speed NFC to Market, but Beware the Risks. 2014. Available online: http://www.pymnts.com/news/2014/ul-hce-can-speed-nfc-to-market-but-beware-the-risks/\#. U2AJMa1_sa8 (accessed on 29 April 2014).

46. Telecom Italia, 2014. Available online: http://www.telecomitalia.com/tit/it/innovation/hot-topics/ mobile/NFC-auto.html (accessed on 29 April 2014).

47. Buhalis, D.; Law, R. Progress in information technology and tourism management: 20 years on and 10 years after the Internet-The state of eTourism research. Tour. Manag. 2008, 29, 609-623.

48. Guttenber, D. Virtual reality: Applications and implications for tourism. Tour. Manag. 2010, 31, $637-651$.

49. Wang, D.; Park, S.; Fesenmaier, D.R. The role of smartphones in mediating the touristic experience. J. Travel Res. 2012, 51, 371-387.

50. Ricci, F. Mobile recommender systems. Inf. Technol. Tour. 2010, 12, 205-231.

51. Pesonen, J.; Horster, E. Near field communication technology in tourism. Tour. Manag. Perspect. 2012, 4, 11-18. 
52. Egger, R. The impact of near field communication on tourism. J. Hosp. Tour. Technol. 2013, 4, 119-133.

53. Madlmayr, G.; Scharinger, J. Neue Dimensionen von Mobilen Tourismusanwendungen Durch Near Field Communication Technologie. In mTourism. Mobile Dienste im Tourismus Wiesbaden; Egger, R., Jooss, M., Eds.; Gabler Verlag: Wiesbaden, Germany, 2010; pp. 75-88.

54. DEVCO and UNWTO. Sustainable Tourism for Development. 2013. Available online: http://icr.unwto.org/content/guidebook-sustainable-tourism-development (accessed on 24 June 2014).

55. GSMA. The Benefits of Mobile NFC for Air Travel, White Paper Version 1.0-Non Confidential, 2011. Available online: http://www.iata.org/whatwedo/passenger/fast-travel/Documents/ iata-public-whitepaper-issue1.pdf (accessed on 26 June 2014).

56. Clark, S. SAS to Introduce NFC to Airports, 2011. Available online: http://www.nfcworld.com/ 2011/06/15/38035/sas-to-introduce-nfc-to-airports (accessed on 26 June 2014).

57. Clark, S. London Taxi Firm Promotes App Downloads with NFC and QR Stickers. 2014. Available online: http:/www.nfcworld.com/2014/05/20/329236/london-taxi-firm-promotes-appdownloads-nfc-qr-stickers/ (accessed on 26 June 2014).

58. Clark, S. Rio Gets 5,000 NFC Tags. 2014. Available online: http://www.nfcworld.com/ 2014/06/20/329851/rio-gets-5000-nfc-tags/ (accessed on 24 June 2014).

59. Clark, S. NFC Phones Replace Room Keys and Eliminate Check-In at Swedish Hotel. 2010. Available online: http:/www.nfcworld.com/2010/11/03/34886/nfc-keys-hotelsweden/ (accessed on 29 April 2014).

60. Clarion Hotel Stockholm, NFC Project. Available online: http://www.clarionstockholm.com/ nfc-project (accessed on 29 April 2014).

61. Boden, R. Spanish Hotel Delivers Guest Information via NFC. 2013. Available online: http://www.nfcworld.com/2013/07/24/325127/spanish-hotel-delivers-guest-information-via-nfe/ (accessed on 24 June 2014).

62. Ho, T.; Chen, R. Leveraging NFC and LBS technologies to improve user experiences. In Proceedings of the 2011 International Joint Conference on Service Sciences, Taipei, Taiwan, 25-27 May 2011; pp. 17-21.

63. Argueta, D.; Lu, Y.T.; Ma, J.; Rodriguez, D.; Yang, Y.H.; Phan, T.; Jeon, W. Enhancing the restaurant dining experience with an NFC-enabled mobile user interface. In Mobile Computing, Applications, and Services 5th International Conference, MobiCASE 2013, Paris, France, November 7-8, 2013, Revised Selected Papers; Springer International Publishing Cham: Dordrecht, The Netherlands, 2014; pp. 314-321.

64. Clark, S. Google Confirms Commitment to NFC with New Google Wallet App. 2013. Available online: http://www.nfcworld.com/2013/09/17/325947/google-confirms-commitment-nfc-newgoogle-wallet-app/ (accessed on 26 June 2014).

65. Google Wallet. 2014. Available online: http:/www.google.com/wallet/faq.html\#tab=faq-general (accessed on 26 June 2014).

66. Clark, S. Museum of London Adds NFC. 2011. Available online: http://www.nfcworld.com/ 2011/08/16/39129/museum-of-london-adds-nfc/ (accessed on 29 April 2014). 
67. Ceipidor, U.B.; Medaglia, C.M.; Volpi, V.; Moroni, A.; Sposato, S.; Carboni, M.; Caridi, A. NFC technology applied to touristic-cultural field: A case study on an Italian museum. In Proceedings of the 2013 5th International Workshop on Near Field Communication (NFC), Zürich, Switzerland, 5 February 2013; pp. 1-6.

68. Clark, S. Sydney Picks NFC and QR Codes to Guide Visitors around the Rocks. 2012. Available online: http://www.nfcworld.com/2012/07/02/316609/sydney-picks-nfc-and-qr-codesto-guide-visitors-around-the-rocks/ (accessed on 24 June 2014).

69. Lindsey, J. Vail's EpicMix App Brings Location Tracking, Social Networking to Ski Slopes. 2010. Available online: http://www.wired.com/playbook/2010/09/vails-epicmix-app (accessed on 26 June 2014).

70. Boden, R. NFC Lamp Post Information Service to Launch in Tokyo. 2013. Available online: http://www.nfcworld.com/2013/05/24/324237/nfc-lamp-post-information-service-to-launch-in-tokyo/ (accessed on 24 June 2014).

(C) 2014 by the authors; licensee MDPI, Basel, Switzerland. This article is an open access article distributed under the terms and conditions of the Creative Commons Attribution license (http://creativecommons.org/licenses/by/3.0/). 